\title{
ASPECTOS GERAIS SOBRE AS RELAÇÕES TRABALHISTAS E O MICROEMPREENDEDOR INDIVIDUAL COMO PRESTADOR DE SERVIÇOS A OUTRA PESSOA JURÍDICA
}

\author{
Luis Gustavo Esse \\ Universidade do Oeste Paulista - UNOESTE, Presidente Prudente, SP. E-mail: Igesse33@gmail.com
}

\begin{abstract}
RESUMO
Este artigo, tem por objetivo abordar um fenômeno bastante recente, que consiste na contratação de prestadores de serviços, formalizados como Microempreendedores Individuais (MEI), para executar atividades-fim da empresa contratante, mediante contrato de prestação de serviços, celebrado entre as partes. Este fenômeno surge, sobretudo, a partir da vigência da Lei das Terceirizações (2017), que permitiu a terceirização irrestrita de todas as atividades desempenhadas pela empresa, fazendo com que, atividades que anteriormente só poderiam ser desempenhadas pelo empregado, passaram estar sujeitas a serem realizadas $\mathrm{p}$ or terceirizados, que muitas vezes, são prestadores de serviços individuais, formalizados como Microempreendedores Individuais. O objetivo deste artigo, é demonstrar quais são os impactos jurídicos, e por consequência, os impactos para a gestão da empresa, da adoção desta modalidade de contratação, evidenciando quais são os seus limites e riscos para o empresário.
\end{abstract}

Palavras-chave: MEl. Terceirização. Prestadores de Serviços. Legislação. Recursos Humanos.

\section{GENERAL ASPECTS ABOUT LABOR RELATIONS AND THE INDIVIDUAL MICRO ENTREPRENEUR AS A SERVICE PROVIDER TO ANOTHER LEGAL ENTITY}

\begin{abstract}
This article aims to address a very recent phenomenon, which consists of contracting service providers, formalized as Individual Microentrepreneurs (MEI), to carry out core activities of the contracting company, through a service provision contract, entered into between the parties. This phenomenon arises, above all, from the effectiveness of the Outsourcing Law (2017), which consumes the unrestricted outsourcing of all activities performed by the company, causing activities that can only be performed by functions to be outsourced before by outsourcers, who are often individual service providers, formalized as Individual Microentrepreneurs. The objective of the article is to demonstrate what are the legal acts, and consequently, the acts for the management of the company, of the adoption of this type of contract, showing what are its limits and risks for the entrepreneur.
\end{abstract}

Keywords: MEI. Outsourcing. Service providers. Legislation. Human Resources.

\section{INTRODUÇÃO}

Desde o começo da década anterior, iniciou-se um relevante movimento, por parte do poder público, voltado ao combate da informalidade dos pequenos negócios no Brasil. Inicialmente, a Lei Complementar no. 123/2006 (Estatuto da Micro e Pequena Empresa) serviu como um instrumento de base para todo este movimento de combate à informalidade, que intensifica-se a partir do ano de 2008, com a Lei Complementar no. 128/2008, que estabelece a figura do Microempreendedor Individual (MEI), que tornou-se, a partir de então, o mecanismo mais simplificado para promover a formalização 
dos pequenos negócios no país. (BRASIL, 2006, 2008)).

Voltado unicamente para a formalização de atividades estritamente empresariais, neste sentido, excluem-se os profissionais liberais e demais profissões intelectuais, conforme previsto no artigo 966, do vigente Código Civil Brasileiro, a possibilidade de formalização como Microempreendedor Individual acabou por se tornar um caminho extremamente simplificado para a formalização, uma vez que possui um sistema bastante simplificado, facilitando a obtenção do Cadastro Nacional de Pessoas Jurídicas (CNPJ), por parte do formalizando, além de assegurar ao novo empresário, uma previsibilidade de suas despesas com tributos, uma vez que a guia mensal de tributos, possui valor fixo, independente do faturamento obtido pelo $\mathrm{MEI}$, conforme prevê o artigo 18-A, § 3으, inciso V, da Lei Complementar no. 123/2006.

Ocorre que, o que seria inicialmente uma ferramenta apenas voltada a formalizar 0 pequeno empresário, que muitas vezes trabalhava sozinho ou com o auxílio de mais um colaborador, acaba por se tornar um importante mecanismo para intensificar a terceirização das atividades, no âmbito empresarial, em especial após a Lei no. 13.429/2017 (Lei das Terceirizações), que, muito embora não preveja a permissão da terceirização mediante a contratação de Microempreendedores Individuais, também não proíbe esta prática, sendo, na realidade, a referida legislação, completamente omissa a esta prática, que tem se tornado cada vez mais frequente. (BRASIL, 2017)

Por fim, importante salientar ainda que, a Lei das Terceirizações, permitiu a terceirização de "atividades-meio" e "atividades-fim" das empresas, conforme alteração realizada no teor do artigo 9o, § 3으, da Lei ํo. 6.019/1974, que acabou por permitir a terceirização completa de todas as atividades desempenhadas pela empresa principal, resultando em uma transferência significativa dos riscos de sua atividade a terceiros, o que, claramente, tem resultado em diversos questionamentos, perante - Poder Judiciário, sobretudo envolvendo Microempreendedores Individuais, contratados para exercerem funções que anteriormente seriam típicas de funcionários exercendo a "atividade-fim" da empresa.(BRASIL, 1974)

\section{MÉTODOS}

A pesquisa apresentada por este artigo, foi realizada utilizando a pesquisa documental, utilizando-se como referencial teórico, outras publicações, sejam em revistas científicas ou em diários oficiais, a fim de estudar o fenômeno ora apresentado.

\section{DISCUSSÃO E RESULTADOS}

Primeiramente, é importante frisar que o Microempreendedor Individual pode prestar serviços a outras pessoas jurídicas, sendo esta uma conduta permitida em lei, contudo, acerca da possibilidade do Microempreendedor Individual (MEI) figurar como empresa terceirizadora de mão-de-obra, surgem algumas discussões, neste sentido, sobre esta possibilidade ou não.

De início, se considerarmos o teor da Lei no. 6.019/1974, não existe qualquer impeditivo legal, para que o MEl seja reconhecido como uma empresa terceirizadora de mão-de-obra, contudo, é importante frisar que o MEI somente pode possuir um único empregado, motivo pelo qual, no caso de terceirização de mão-de-obra, os serviços prestados pela empresa $\mathrm{MEl}$, muito provavelmente seriam feitos por prestação pessoal do empresário contratado. (BRASIL, 1974).

Diante desta possibilidade do empresário MEl estar prestando, pessoalmente, os serviços a empresa contratante, o empresário MEI passa a ocupar duas posições na relação contratual: a primeira, como empresário tomador de serviços, quando desempenha seu papel de pessoa jurídica; a segunda, como o efetivo prestador de serviços, desempenhando seu papel de pessoa física.

Esta dualidade de papeis, faz com que seja questionada a própria existência da terceirização, pois, conforme anteriormente dito, embora seja perfeitamente admissível o fato do MEI desempenhar a função de prestador de serviços, a terceirização não admite que o prestador de serviços tenha vínculo de subordinação diretamente com a empresa contratante, embora esteja a serviço desta, ele não pode estar subordinado a esta, conforme explica Raquel de Siqueira Martins, acerca da subordinação dos terceirizados: Os prestadores de serviço são subordinados à empresa tomadora $e$ ainda existe pessoalidade nessa relação (MARTINS, 2016). 
Neste sentido, o Microempreendedor Individual, quando exerce esta dualidade de papeis, ele pode acabar se subordinando às ordens da empresa contratante, o que descaracteriza a prestação de serviços, conforme explica Gustavo Filipe Barbosa Garcia, conforme segue: "Se, com o fim de terceirizar certa atividade, for contratada empresa prestadora, mas o tomador exercer o poder diretivo perante $o$ trabalhador, este, certamente, na realidade, passa a ter sua relação jurídica de emprego com o próprio tomador" (GARCIA, 2008).

Desta forma, o empresário $\mathrm{MEI}$, quando sujeita-se às ordens da empresa contratante, pode estar descaracterizando a relação de prestação de serviços e, por consequência, de terceirização de mão-de-obra, fazendo configurar a relação de vínculo empregatício, nos termos do Art. 3o, da Consolidação das Leis do Trabalho (CLT). Neste caso, ainda que, em tese, exista uma vedação legal, em virtude da existência da pessoa jurídica, para caracterizar o MEI como empregado, não podemos esquecer, que a prestação de serviços é realizada por uma pessoa física, e, em razão deste fato, é possível a caracterização do vínculo empregatício da pessoa física, que desempenha a função, junto a empresa contratante da prestação de serviços, caso configuradas as elementares que configuram o vínculo empregatício (subordinação, habitualidade, onerosidade e pessoalidade).

Recentemente, diversas lides judiciais foram ajuizadas, com o intuito de discutir sobre a existência (ou não) do vínculo empregatício, envolvendo este tipo de terceirização, havendo relevante discussão neste sentido. Primeiramente, o Tribunal Regional do Trabalho da 2a Região (TRT-2), possui julgado no sentido de que, se preenchidas as elementares do Art. $3^{\circ}$, da CLT, conforme segue ementa do julgado:

$\begin{array}{lr}\text { Ementa } & \text { RECURSO } \\ \text { ORDINÁRIO DA } & \text { SEGUNDA } \\ \text { RECLAMADA } & \text { Da } \\ \text { responsabilidade } & \\ \text { subsidiária Ainda } & \text { que a } \\ \text { hipótese sejararano de } & \text { com } \\ \text { terceirização, de serviços } \\ \text { transferência de } \\ \text { especializados, ou que se } \\ \text { afirme que a legislação e a } \\ \text { jurisprudência } \\ \text { caminharam no sentido de } \\ \text { permitir que determinada } \\ \text { empresa especializada }\end{array}$

ofereça seus préstimos a outras, isso não autoriza a exploração do trabalho humano, o desrespeito ao princípio da dignidade humana e o império do lucro a qualquer custo. A segunda reclamada beneficiou-se da força de trabalho do reclamante, cabendo, assim, a assunção da responsabilidade subsidiária para garantir o adimplemento de prestações obrigacionais que eventualmente não venham a ser honradas pela primeira reclamada. Mantenho. Diante $d a$ identidade das matérias, analiso em conjunto os apelos interpostos nos tópicos a seguir. Do vínculo empregatício Muito embora tenha sido formalizado o contrato abojado aos autos, firmado entre a primeira ré e o autor, na condição de microempreendedor individual, as provas testemunhal $e$ documental revelam que este prestava serviços em favor das rés com pessoalidade, onerosidade, não eventualidade $e$ subordinação, requisitos esses que caracterizam a relação de emprego prevista no artigo 3o da CLT. Mantenho a $r$. sentença. (...)

O Tribunal Regional do Trabalho da 15a Região (TRT-15), por sua vez, possui julgado, com uma explicação mais contundente, do que seria a caracterização do vínculo empregatício, sob o viés de uma "mão-dupla", ou seja, não basta apenas não configurar as elementares do Art. 3으, da CLT, mas também, prova de existência de relação comercial entre a contratante e a contratada, para que não se configure vínculo empregatício, conforme segue trecho do inteiro teor, da decisão mencionada: 
Para a configuração do vínculo de emprego é necessária a presença, de forma concomitante, dos seguintes pressupostos: habitualidade,

pessoalidade, onerosidade

$e$ subordinação, nos termos do art. 3 da CLT.

(...)

E, mesmo que a reclamante promovesse sua empresa individual no facebook em data anterior à data do registro no Órgão competente, como podemos ver das publicações na rede social datadas de janeiro $e$ fevereiro de 2017, por si só não afasta os elementos caracterizadores do vínculo empregatício e não comprova que a autora laborava de forma autônoma, até porque não há nos autos qualquer documento que demonstre algum vínculo comercial entre o réu e a empresa da autora. (...)

Neste sentido, analisando conjuntamente ambas as decisões, chegamos à conclusão que a prestação de serviços, que pode ser desempenhada pelo $\mathrm{MEI}$, deve ter natureza comercial, aonde as partes possam ajustar livremente os termos da contratação, sem que ocorra subordinação de uma parte aos interesses da outra. Caso isto ocorra, é pacífico o entendimento de que a referida relação contratual poderá ensejar em reconhecimento de vínculo empregatício, uma vez que, embora o MEI também seja uma pessoa jurídica, é evidente que este está em condição de maior vulnerabilidade em relação a empresa contratante que, muitas vezes, costuma ter situação financeira melhor que a do MEI.

Contudo, antes de nos remetermos a etapa conclusiva deste trabalho, é importante delimitar alguns pontos, que necessitam ser elucidados, para assegurar um melhor entendimento das normas e da jurisprudência sobre esta modalidade de contratação. Primeiramente, dentre estes pontos que merecem ser frisados, é delimitar a diferença do trabalho terceirizado, com aquele que possui vínculo empregatício. Neste sentido, a desembargadora do Tribunal Regional do Trabalho da 1a Região (TRT-1), Vólia Bomfim Cassar, nos esclarece que o trabalho temporário, decorrente da permissibilidade da Lei no. 13.429/2017, deveria possuir caráter temporário, conforme de seu artigo Terceirização ampla e irrestrita? Entenda a Lei 13.429/17 que altera a redação da Lei no 6.019/74, destacado a seguir:

Apesar de regulamentada a terceirização geral por empresas prestadoras de serviço, que não se confundem com as empresas de trabalho temporário, esta não pode ocorrer em atividade-fim, pois a lei não foi expressa nesse sentido, como o foi para $o$ trabalho temporário. Entretanto, essa é apenas uma interpretação entre as muitas que surgirão e só o tempo pacificará as inúmeras controvérsias. (CASSAR, 2017)

De acordo com a interpretação da ilustre jurista e magistrada, verificamos que houve uma flexibilização da regra anteriormente vigente, contudo, esta nova permissibilidade não é total e irrestrita, a ponto que o trabalhador terceirizado, não pode ser contratado com a finalidade de substituir, de forma permanente, o empregado da empresa, no que diz respeito a execução da atividade-fim, contudo, o principal questionamento, neste caso em tela, seria delimitar, o que é a atividade-fim de uma empresa, o que certamente comporta muitas divergências e diversas interpretações.

Por este motivo, antes de nos prolongarmos acerca da discussão sobre o que seria atividade-fim de uma empresa, utilizando-se de casos hipotéticos, é fundamental delimitar as diferenças do trabalhador empregado com o trabalhador terceirizado. Primeiro ponto, como já adiantado neste trabalho, o trabalhador empregado precisa preencher aos requisitos do Art. 3으, da Consolidação das Leis do Trabalho (CLT), o que não se verifica, por completo, no caso do trabalhador terceirizado, uma vez que este último possui vínculo trilateral, ou seja, o profissional terceirizado, primeiro ele se reporta a empresa tomadora de serviços, com quem ele 
possui vínculo empregatício direto, e a empresa tomadora de serviços, reporta a empresa contratante, aonde o profissional terceirizado irá executar suas atividades. Neste caso, a empresa tomadora de serviços, ela tem obrigação de assegurar a prestação do serviço, contudo, não possui a obrigação de que aquele serviço seja prestado por aquele profissional em específico, podendo enviar para a empresa, qualquer um de seus funcionários, para a realização do serviço, pois do contrário, haveria a caracterização da pessoalidade, que é um dos elementos necessários para a configuração do vínculo empregatício, de acordo com a legislação vigente.

Ocorre que, no caso de um tomador de serviços Microempreendedor Individual (MEI), que geralmente não possui nenhum empregado, este acaba por prestar o serviço de forma pessoal, descaracterizando, na prática, o vínculo trilateral, caracterizando a existência de vínculo empregatício, ainda que, na teoria, este vínculo exista, uma vez que a empresa contratante está celebrando contrato com a empresa tomadora de serviços, não com a pessoa do prestador de serviços. Contudo, importante frisar que, existem hipóteses que, o MEI poderá possuir um único empregado, neste caso, a prestação de serviço sendo realizada por este empregado, o vínculo trilateral não é prejudicado.

Outro ponto de fundamental importância, que não pode ser olvidado, é sobre a duração do contrato de prestação de serviços. Conforme explicado pela desembargadora Vólia Bonfim Cassar, a contratação do serviço terceirizado, deveria ser de caráter temporário, contudo, devemos nos relembrar que a própria Consolidação da Lei dos Trabalhos (CLT) também contempla a possibilidade de celebração do contrato de trabalho, entre empregador $\mathrm{e}$ empregado, por prazo determinado. Neste sentido, é importante delimitar a diferença entre o trabalhador terceirizado e o trabalhador empregado com caráter temporário. Neste sentido, além dos direitos trabalhistas, inerentes a todo trabalhador contratado sob o regime da $\mathrm{CLT}$, o trabalhador terceirizado tem liberdade para estabelecer a forma que será executado o serviço que está prestando, comprometendo-se apenas com a entrega do resultado ao contratante, diferente do trabalhador empregado, ainda que na forma de contrato temporário, que deve sujeitar-se as regras do empregador, no que diz respeito a forma de execução que por este é estabelecida.
Ocorre que, conforme ressaltado anteriormente, neste trabalho, a ausência prática da relação trilateral, na prestação de serviços desempenhada por Microempreendedor Individual (MEI), pode afastar, em alguns casos, esta liberdade de execução das atividades, que é típica das relações de prestação de serviços, principalmente em situações em que é confusa a delimitação da atividade-fim da empresa. Neste sentido, é preciso nos atentar que sempre existirão diferenças entre a teoria e a prática, principalmente no que diz respeito a aplicabilidade de normas jurídicas.

\section{CONCLUSÃO}

Um dos principais motivos que as empresas recorrem a terceirização de mão-deobra, está intrinsicamente relacionado a redução de custos com recursos humanos, contudo, nem sempre esta terceirização é legítima, sendo que, não são raros os casos em que o funcionário da empresa terceirizada, acaba por submeter-se a ordem diretas da empresa contratante, passando a atuar, na prática, como se fosse empregado da empresa contratante, e não da empresa tomadora de serviços.

No caso dos Microempreendedores Individuais, em razão da impossibilidade de dissociar, na maioria dos casos, a pessoa do empresário, com a pessoa de quem efetivamente executará a prestação de serviços, acaba por ser impossível a configuração da subordinação com a empresa tomadora de serviços, fazendo com que ocorra, na prática, a subordinação com a empresa contratante, o que, de acordo com a jurisprudência apresentada, claramente configura o vínculo empregatício.

Neste sentido, o empresário que busca recorrer a prestadores de serviços, formalizados como Microempreendedores Individuais (MEI), devem tomar certa cautela, a fim de que evitem utilizarem-se deste artifício, apenas com o intuito de livrar-se das despesas da contratação de um empregado, uma vez que, caso a empresa resolva contratar o MEI, sujeitando-o as elementares constitutivas do vínculo empregatício, ainda que tente respaldar-se documentalmente, poderá este vínculo ser reconhecido judicialmente, descaracterizando a suposta relação de prestação de serviço, entre duas pessoas jurídicas.

Insta salientar ainda que, existem situações em que é difícil delimitar qual seria a atividade fim de determinada empresa, pois podem existir divergências entre o que ela 
declara como sendo sua atividade fim, em relação ao que ela efetivamente executa como sendo atividade fim. Para fins hipotéticos, imaginemos uma construtora, que realiza a construção de imóveis de baixo custo e, ao invés de contratar corretores de imóveis, contrata microempreendedores individuais (MEI), formalizados como promotores de vendas, para realizar a comercialização destes imóveis. Neste cenário hipotético, alguns questionamentos podem ser realizados, como por exemplo: a atividade-fim da empresa é a construção civil apenas ou a comercialização de imóveis próprios; os promotores de vendas, possuem liberdade para executar as vendas, a fim de atingir os resultados pactuados com a empresa contratante, ou devem seguir parâmetros préestabelecidos com esta empresa, a fim de definir como executarão esta atividade. Estes questionamentos, abrem espaço para inúmeros questionamentos e análise de cada caso, individualmente.

Desta forma, é evidente que, diante do crescente aumento deste tipo de contratação, deverá o legislador, em momento oportuno, regulamentar este tipo de contratação, a fim de especificar os limites de contratação do Microempreendedor Individual como prestador de serviços, reconhecendo sua vulnerabilidade em relação às demais pessoas jurídicas de porte maior, não podendo prevalecer a ideia de igualdade entre as partes, o poder econômico da pessoa jurídica de porte maior, pode prejudicar os interesses do microempreendedor individual, neste tipo de relação contratual.

\section{REFERÊNCIAS}

BRASIL. Presidência da República

Casa Civil. Lei no. 6.019/1974. Brasília: Presidência da República, 1974.

BRASIL. Presidência da República

Casa Civil. Lei no. 10.406/2002 (Código Civil Brasileiro). Brasília: Presidência da República, 2002.

BRASIL. Presidência da República

Casa Civil. Lei Complementar no. 123/2006.

Brasília: Presidência da República, 2006.

BRASIL. Presidência da República

Casa Civil. Lei Complementar no. 128/2008.

Brasília: Presidência da República, 2008.
BRASIL. Presidência da República

Casa Civil Lei no. 13.429/2017. Brasília: Presidência da República, 2017.

CASSAR, V. B. Terceirização ampla e irrestrita? Entenda a Lei 13.429/17 que altera a redação da Lei $n=6$ 6.019/74. Publicado em: 05/04/2017.

Disponível em:

https://www.Ifg.com.br/conteudos/artigos/geral /terceirizacao-ampla-e-irrestrita-entenda-a-lei1342917-que-altera-a-redacao-da-lei-n-601974.. Acesso em: 17 jun. 2021.

GARCIA, G. F. B. Curso de Direito do Trabalho. 2. ed. São Paulo: Método, 2008.

MARTINS, R. S. Terceirização - os limites da responsabilidade do tomador de serviços. Disponível em: https://ambitojuridico.com.br/edicoes/revista154/terceirizacao-os-limites-da-responsabilidadedo-tomador-de-servicos/\#_ftn13. Publicado em: 01/11/2016. Acesso em: 30 maio 2021.

TRIBUNAL REGIONAL DO TRABALHO DA 2a REGIÃO (TRT-2). Recurso Ordinário Trabalhista no. 1000542-20.2019.5.02.0045. São Paulo, TRT2, 2021.

TRIBUNAL REGIONAL DO TRABALHO DA 15a REGIÃO (TRT-15). Recurso Ordinário no. 0011526-63.2017.5.15.0021. Campinas: TRT-15, 2021. 